\title{
CrystEngComm
}

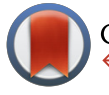

Cite this: CrystEngComm, 2016, 18, 8898

Received 27th July 2016,

Accepted 21st October 2016

DOI: $10.1039 / c 6 c e 01650 b$

www.rsc.org/crystengcomm
CrossMark click for updates

\section{Structural transformations in crystals induced by radiation and pressure. Part 4 . The complex influence of high pressure on the path and kinetics of the [2+2] photodimerization $\dagger$}

\author{
J. Bąkowicz* and I. Turowska-Tyrk
}

\begin{abstract}
The results from monitoring structural changes brought about by the $[2+2]$ photodimerization of 2-benzyl-5-benzylidenecyclopentanone (BBCP) in crystals at high pressure were presented. This is one of the two first examples of such studies for an intermolecular reaction. The influence of pressure of $0.5 \mathrm{GPa}$ on the extent of changes caused by the photochemical reaction in the cell volume, in the molecular orientation and in the distance between reactive atoms is the same or similar to for $0.1 \mathrm{MPa}$ of pressure, however, the character of the changes in the above-mentioned distance is different. The reason for the observed close similarity between the reaction path at $0.1 \mathrm{MPa}$ and $0.5 \mathrm{GPa}$ is a very good fit for dimer molecules to the crystal lattice of the monomer. The influence of high pressure itself on (a) the volume of the unit cell, (b) the volume of the free space in the unit cell, (c) the geometry of intermolecular interactions and (d) the distance between directly reacting atoms of two adjacent molecules was also described. The reaction rate is greater at $0.7 \mathrm{GPa}$ than at $0.5 \mathrm{GPa}$; however, the difference is small. This was explained by the consistency between structural changes that came about by the photochemical reaction and by high pressure.
\end{abstract}

\section{Introduction}

From the scientific literature, it is known that 2-benzyl-5benzylidenecyclopentanone (BBCP) under UV-vis radiation under ambient conditions undergoes the $[2+2]$ photodimerization in crystals and that this reaction can proceed in a homogeneous manner. ${ }^{1-5}$ The formula of BBCP and the equation of the $[2+2]$ photodimerization are presented in Scheme 1 . The path of the structural changes created by this photochemical reaction in crystals under ambient conditions was studied in the past. ${ }^{3,4}$ It was discovered that molecules of the reactant (monomer) and of the product (dimer) change their position during the phototransformation of crystals. The product molecules move towards the position occupied in the pure product crystals and the reactant molecules move away from the position occupied in the pure reactant crystals. The molecular movements have a rotational component. Additionally, it was found that the adjacent monomer molecules

Faculty of Chemistry, Wroctaw University of Science and Technology, Wybrzeże Wyspiańskiego 27, 50-370 Wroctaw, Poland. E-mail: julia.bakowicz@pwr.edu.pl; Fax: +48713203364

$\dagger$ Electronic supplementary information (ESI) available. CCDC 1491722-1491731, 1496289-1496290. For ESI and crystallographic data in CIF or other electronic format see DOI: 10.1039/c6ce01650b moved closer to each other along with the progress of the phototransformation of crystals.

High pressure itself also causes changes in crystal structures, such as shortening of intermolecular distances, modification of molecular orientation and decrease of volume and elasticity of reaction cavities. ${ }^{6-13}$ It can also reduce structural changes that come about by photochemical reactions and influence reaction kinetics. ${ }^{12}$

Until now, crystallographic studies on monitoring a course of photochemical reactions at high pressure have been carried out for intramolecular photocyclization reactions, namely, for the formation of a five-membered ring in 2-tertbutylphenylphenylmethanone and a four-membered ring (the Norrish-Yang reaction) in 4-(2,4,6-triisopropylbenzoyl)benzoate benzylammonium and 6,6-diethyl-5-oxo-5,6,7,8tetrahydronaphthalene-2-carboxylate (1S)-1-(4-methylphenyl)ethylammonium ${ }^{11-13}$ and for [2+2] photodimerization of 2,6-

2
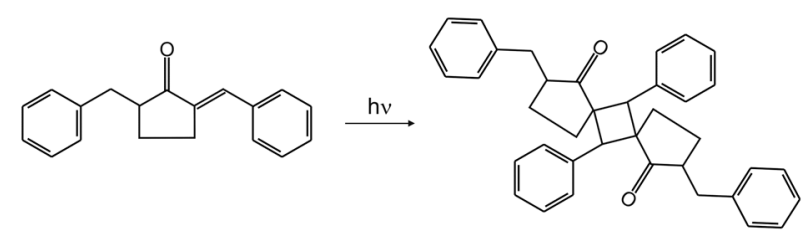

Scheme 1 The equation of the $[2+2]$ photodimerization of BBCP. 
difluorocinnamic acid. ${ }^{14}$ It is worth adding that Boldyreva and co-workers studied the effect of high pressure on the photochemical nitro-nitrito isomerization on the grounds of analysis of pure component crystalline materials (cobalt(III) nitro- and nitritopentaammoniates) using X-ray diffractometry and IR spectroscopy. ${ }^{10,15,16}$ In this paper, we have presented the results of the studies from monitoring the structural transformations brought about by the $[2+2]$ photodimerization of BBCP at high pressure and the comparison with the respective data for ambient pressure.

\section{Experimental}

The crystals of BBCP were recrystallized from toluene. The high pressure studies were carried out for four of them at 0.5, 0.7, 1.0 and $1.2 \mathrm{GPa}$, respectively. Each crystal was separately placed in a Boehler-Almax ${ }^{17}$ or a Merrill-Bassett ${ }^{18}$ high pressure cells (DAC) together with a quartz crystal. The quartz served as a high-pressure sensor: the values of pressure were determined on the grounds of its cell parameters. ${ }^{19}$ As a hydrostatic liquid, a mixture of glycerin and water $(3: 2)$ was used. The DAC was mounted on a diffractometer and aligned using the gasket-shadow centering procedure. ${ }^{20}$ The $\mathrm{X}$-ray data were collected by means of a single-crystal X-ray diffractometer equipped with an EOS CCD detector in the dark. The CrysAlisPro program suite ${ }^{21}$ was used for the data collection, UB matrices determination and data reduction. Additional corrections of reflection intensities, associated with DAC absorption, were used for the partially reacted crystal structures at $0.5 \mathrm{GPa}$. In the case of the remaining structures, the absorption corrections did not improve the data.

The photochemical reaction was induced by UV radiation in the dark. The crystals in DAC were irradiated in stages using an $\mathrm{Hg} 100 \mathrm{~W}$ lamp equipped with a water filter and a BG-39 Andover glass filter. The BG-39 glass filter has a maximum transmittance at about $495 \mathrm{~nm}$ and a cut-on at about $320 \mathrm{~nm}$. The chosen filter ensured homogeneity of the studied photochemical reaction. ${ }^{22,23}$ It was a result of our estimates that $99 \%$ of UV radiation was absorbed in the crystal layer of $0.12 \mathrm{~mm}$ for the wavelength of $325 \mathrm{~nm}$ (the wavelength from the low-energy absorption tail). The thickness of this layer was comparable with the thickness of the studied crystals. This means that the distribution of product molecules was almost uniform throughout the crystals. The time of UV irradiation of the studied crystals and the product concentration are given in Table 1 . The product concentration was provided by the site occupation factor refined during the $\mathrm{X}$-ray structure analysis. The structures were refined using SHELXL2014. ${ }^{24,25}$ The initial coordinates for the purecomponent crystals were taken from the structure determined under ambient conditions (CCDC 154265; REFCODE: BZDCPB08). ${ }^{3}$ The phenyl rings for all crystals were refined as rigid rotating groups of geometry also taken from the purecomponent structures determined under ambient conditions. ${ }^{3}$ Most atoms in the partially reacted crystals were refined as disordered atoms over two positions: one for the re-
Table 1 The irradiation time and the product content for the studied crystals

\begin{tabular}{llll}
\hline $\begin{array}{l}\text { Crystal } \\
\text { number }\end{array}$ & $\begin{array}{l}\text { Pressure } \\
{[\mathrm{GPa}]}\end{array}$ & $\begin{array}{l}\text { UV irradiation time } \\
{[\mathrm{sec}]}\end{array}$ & $\begin{array}{l}\text { Product content } \\
{[\%]}\end{array}$ \\
\hline 1 & 0.5 & 0 & $8.8(9)$ \\
& & 30 & $26.2(11)$ \\
& & 60 & $35.4(11)$ \\
& & 90 & $54.4(11)$ \\
& & 150 & $80.1(13)$ \\
2 & 0.7 & 390 & 100 \\
& & 0 & $12.1(7)$ \\
3 & 1.0 & 60 & $49.3(13)$ \\
4 & & 0 & $49.9(11)$ \\
& 1.2 & 0 & 100 \\
& & 600 & $80.4(13)$ \\
& & & 100
\end{tabular}

actant and the second for the product. Due to the reactantproduct disorder, the following weak restraints from SHELXL2014 were applied: DFIX, DANG, FLAT and SIMU. The target values for bond lengths and valence angles were taken from the structures of the pure reactant and pure product crystals under ambient conditions. Due to a small number of observed reflections, most non-hydrogen atoms of reactant and product molecules were refined isotropically. The oxygen atom of the major component was treated anisotropically, except for the crystal structures containing $26.2 \%$ and $54.4 \%$ of the product at $0.5 \mathrm{GPa}$. In the case of the pure dimer crystals at $0.5 \mathrm{GPa}$ and $1.0 \mathrm{GPa}$ and for the partially reacted crystals at $0.7 \mathrm{GPa}$, several atoms in phenyl rings were also refined anisotropically, i.e. C9D $\rightarrow$ C11D and C16D $\rightarrow$ C18D for $0.5 \mathrm{GPa}, \mathrm{C} 8 \mathrm{D} \rightarrow \mathrm{C} 12 \mathrm{D}$ and $\mathrm{C} 15 \mathrm{D} \rightarrow \mathrm{C} 19 \mathrm{D}$ for 1.0 $\mathrm{GPa}$ and $\mathrm{C} 7 \mathrm{M} \rightarrow \mathrm{C} 12 \mathrm{M}$ and $\mathrm{C} 9 \mathrm{M} \rightarrow \mathrm{C} 11 \mathrm{M}$ for the crystals containing 12.1 and $49.3 \%$, respectively, of the product at 0.7 GPa. $\mathrm{M}$ and D denote monomer and dimer molecules. For all structures, hydrogen atoms were positioned geometrically with $U_{\text {iso }}=1.2 U_{\text {eq. }}$.

Selected experimental data are presented in Table 2 for all structures.

It is worth mentioning that in order to check the sensitivity of crystals of BBCP to light filtered through room windows, we collected X-ray data for another crystal kept under day-light conditions at ambient pressure for 2 weeks and afterwards for an additional 4 weeks. The X-ray structure analysis revealed that the product content changed from 28.9(4) to $70.8(4) \%$. This indicated that crystals of BBCP should be stored and experiments should be conducted in the dark.

\section{Results and discussion}

It is clear from our studies that the $[2+2]$ photodimerization of BBCP proceeds in crystals not only at ambient pressure but also under high-pressure conditions and that it proceeds completely. In order to monitor the path and kinetics of this photochemical reaction, the high-pressure structures of crystals containing both the reactant and the product in various proportions were determined. Such crystals feature a 
Table 2 Selected crystallographic data

\begin{tabular}{|c|c|c|c|c|c|c|}
\hline & \multicolumn{6}{|l|}{$0.5 \mathrm{GPa}$} \\
\hline Chemical formula & $\mathrm{C}_{19} \mathrm{H}_{18} \mathrm{O}$ & $\mathrm{C}_{19} \mathrm{H}_{18} \mathrm{O}$ & $\mathrm{C}_{19} \mathrm{H}_{18} \mathrm{O}$ & $\mathrm{C}_{19} \mathrm{H}_{18} \mathrm{O}$ & $\mathrm{C}_{19} \mathrm{H}_{18} \mathrm{O}$ & $\mathrm{C}_{19} \mathrm{H}_{18} \mathrm{O}$ \\
\hline Crystal dimensions (mm) & $0.30 \times 0.20 \times 0.12$ & $0.30 \times 0.20 \times 0.12$ & $0.30 \times 0.20 \times 0.12$ & $0.30 \times 0.20 \times 0.12$ & $0.30 \times 0.20 \times 0.12$ & $0.30 \times 0.20 \times 0.12$ \\
\hline Crystal system & Orthorhombic & Orthorhombic & Orthorhombic & Orthorhombic & Orthorhombic & Orthorhombic \\
\hline Space group & $P b c a$ & Pbca & Pbca & $P b c a$ & $P b c a$ & Pbca \\
\hline$V\left(\AA^{3}\right)$ & $2794(4)$ & $2794(5)$ & $2794(5)$ & $2789(5)$ & $2783(3)$ & $2769(3)$ \\
\hline$Z$ & 8 & 8 & 8 & 8 & 8 & 8 \\
\hline$D_{\mathrm{x}}\left(\mathrm{Mg} \mathrm{m}^{-3}\right)$ & 1.25 & 1.25 & 1.25 & 1.25 & 1.25 & 1.26 \\
\hline$\mu\left(\mathrm{mm}^{-1}\right)$ & 0.08 & 0.08 & 0.08 & 0.08 & 0.08 & 0.08 \\
\hline$T(\mathrm{~K})$ & $299(2)$ & $299(2)$ & $299(2)$ & $299(2)$ & $299(2)$ & $299(2)$ \\
\hline Reflections collected & 11138 & 9980 & 11162 & 11131 & 11099 & 11251 \\
\hline$R(I>2 \sigma(I)) \mathrm{w} R($ all), $\mathrm{S}$ & $0.1180 .379,1.09$ & $0.1370 .424,1.32$ & $0.1330 .435,1.36$ & $0.1460 .450,1.41$ & $0.1200 .373,1.05$ & $0.1030 .304,1.04$ \\
\hline \multirow[t]{3}{*}{$\Delta \rho_{\max }, \Delta \rho_{\min }\left(\mathrm{e} \AA^{-3}\right)$} & $0.19,-0.15$ & $0.16,-0.14$ & $0.16,-0.12$ & $0.17,-0.14$ & $0.22,-0.14$ & $0.16,-0.18$ \\
\hline & \multicolumn{2}{|l|}{$0.7 \mathrm{GPa}$} & \multicolumn{2}{|l|}{$1.0 \mathrm{GPa}$} & \multicolumn{2}{|l|}{$1.2 \mathrm{GPa}$} \\
\hline & $12.1 \% \mathrm{P}$ & $49.3 \% \mathrm{P}$ & $49.9 \% \mathrm{P}$ & $100 \% \mathrm{P}$ & $80.4 \% \mathrm{P}$ & $100 \% \mathrm{P}$ \\
\hline Chemical formula & $\mathrm{C}_{19} \mathrm{H}_{18} \mathrm{O}$ & $\mathrm{C}_{19} \mathrm{H}_{18} \mathrm{O}$ & $\mathrm{C}_{19} \mathrm{H}_{18} \mathrm{O}$ & $\mathrm{C}_{19} \mathrm{H}_{18} \mathrm{O}$ & $\mathrm{C}_{19} \mathrm{H}_{18} \mathrm{O}$ & $\mathrm{C}_{19} \mathrm{H}_{18} \mathrm{O}$ \\
\hline Formula weight & 262.33 & 262.33 & 262.33 & 262.33 & 262.33 & 262.33 \\
\hline Crystal dimensions (mm) & $0.20 \times 0.20 \times 0.12$ & $0.20 \times 0.20 \times 0.12$ & $0.20 \times 0.18 \times 0.16$ & $0.20 \times 0.18 \times 0.16$ & $0.24 \times 0.14 \times 0.10$ & $0.24 \times 0.14 \times 0.10$ \\
\hline Crystal system & Orthorhombic & Orthorhombic & Orthorhombic & Orthorhombic & Orthorhombic & Orthorhombic \\
\hline Space group & $P b c a$ & Pbca & Pbca & $P b c a$ & $P b c a$ & Pbca \\
\hline$a(\AA)$ & $30.934(2)$ & $30.841(2)$ & $30.88(4)$ & $30.68(3)$ & $30.37(3)$ & $30.46(3)$ \\
\hline$b(\AA)$ & $10.379(3)$ & $10.374(3)$ & $10.2558(9)$ & $10.3153(7)$ & $10.2318(12)$ & $10.2338(10)$ \\
\hline Reflections observed & 515 & 451 & 409 & 520 & 404 & 436 \\
\hline Completeness (\%) & 38.6 & 37.6 & 30.8 & 31.5 & 34.0 & 33.9 \\
\hline$R_{\text {int }}$ & 0.118 & 0.150 & 0.097 & 0.088 & 0.144 & 0.134 \\
\hline$R(I>2 \sigma(I)) \mathrm{w} R($ all), $\mathrm{S}$ & $0.0850 .243,1.04$ & $0.1220 .360,1.06$ & $0.0890 .296,1.11$ & $0.0660 .202,1.06$ & $0.0920 .300,1.05$ & $0.1030 .332,1.08$ \\
\hline 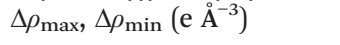 & $0.16,-0.17$ & $0.18,-0.16$ & $0.16,-0.12$ & $0.14,-0.15$ & $0.22,-0.18$ & $0.25,-0.26$ \\
\hline
\end{tabular}

reactant-product disorder. Fig. 1 presents an example of the structure of the partially reacted crystal at high pressure. Knowledge of such structures has allowed us to learn about the behaviour of reactant and product molecules, the kind and extent of structural changes in crystals brought about by the photochemical reaction and about the reaction kinetics. The studies have also provided knowledge of the influence of high pressure on the above-mentioned issues.

The $[2+2]$ photodimerization of BBCP at high pressure is of the first order and proceeds quicker at the beginning than in the final stages. The relationship evidencing this fact, namely the relationship between the percentage content of the product and the time of crystal irradiation, is presented in Fig. 2. The character of this relationship is similar to the one described in the scientific literature for ambient condi- tions. $^{3}$ The analysis of the JMAK kinetic equation ${ }^{27-30}$ confirmed that the $[2+2]$ photodimerization of BBCP proceeds in a homogeneous manner at high pressure. The Avrami exponent $^{27-30}$ for the reaction at $0.5 \mathrm{GPa}$ is $1.04(18)$, which indicates that the formation of the product proceeds with homogenous dispersion. The homogeneity of the $[2+2]$ photodimerization of BBCP in crystals was also observed in the case under ambient conditions (see the Introduction section). The JMAK model is widely used as a description of kinetics of photochemical reactions in crystals. ${ }^{31-36}$

The reaction rate is greater at $0.7 \mathrm{GPa}$ than at $0.5 \mathrm{GPa}$. At $0.5 \mathrm{GPa}$, the product content in the crystal changed from $8.8(9)$ to $35.4(11) \%$ after $60 \mathrm{~s}$ of $\mathrm{UV}$ irradiation. At $0.7 \mathrm{GPa}$, the product content changed more in the same time, namely from $12.1(7)$ to $49.3(13) \%$. The difference in the reactivity is 
(a)

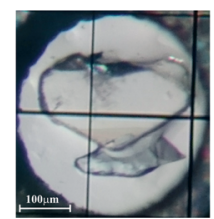

(b)

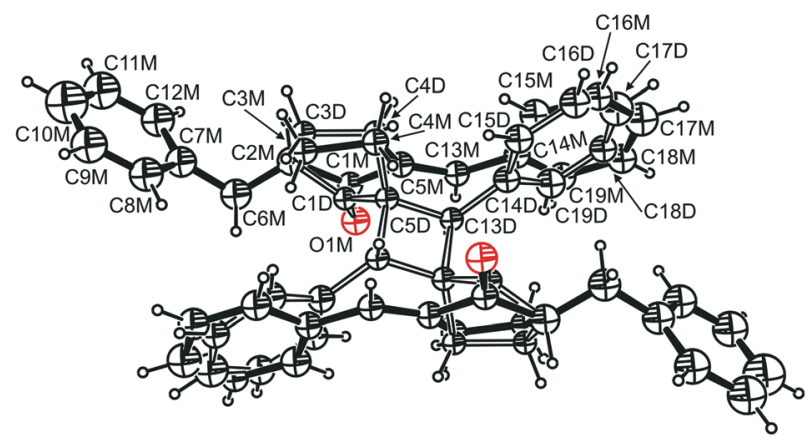

Fig. 1 (a) The BBCP (top) and quartz (bottom) crystals at $0.5 \mathrm{GPa}$. (b) Two monomer molecules superimposed on one dimer molecule in the crystal of $54.4(11) \%$ reaction progress at $0.5 \mathrm{GPa}$, prepared by means of ORTEP software. ${ }^{26}$ The dimer molecule lies about an inversion centre (for all crystal structures). Atomic displacement parameters are drawn at a $20 \%$ probability level.

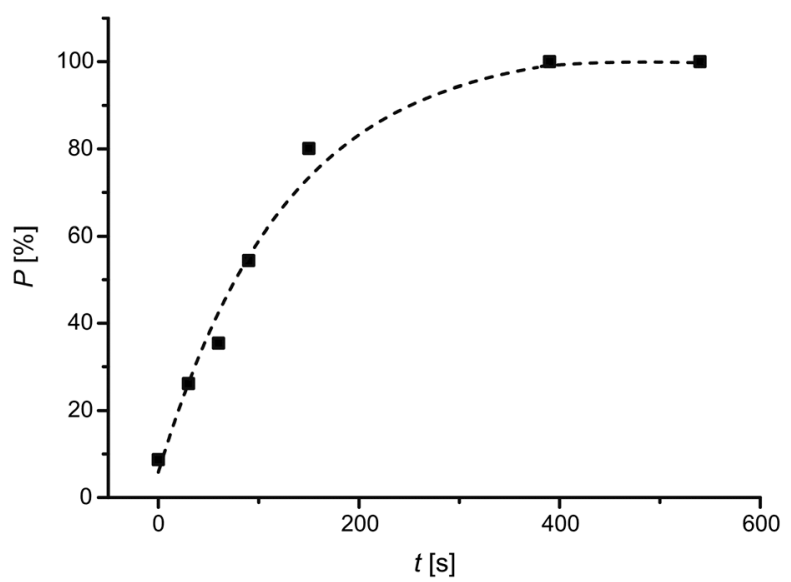

Fig. 2 The relationship between the product content and the time of crystal irradiation at $0.5 \mathrm{GPa}$.

not very high, but statistically significant. The comparison of the reaction rate at $0.5 \mathrm{GPa}$ with the relevant literature data for $0.1 \mathrm{MPa}$ cannot be carried out because of slightly different crystal dimensions and experimental conditions applied in the past at $0.1 \mathrm{MPa}^{3}$ Nevertheless, the comparison between the structural changes at both pressures can be made. The increase of photochemical reactivity along with high pressure was also observed in the case of 2,6difluorocinnamic acid. ${ }^{14}$

What are the reasons for the $[2+2]$ photodimerization of $\mathrm{BBCP}$ proceeding with a greater rate at $0.7 \mathrm{GPa}$ than at 0.5 GPa? The following factors should be considered in order to address this question, namely: the distance between adjacent monomer molecules, the volume of the unit cell, the volume of free space in crystals and the force of intermolecular interactions.

In general, the shorter the distance between reacting atoms, the quicker the $[2+2]$ photodimerization should be. Applying high pressure to crystals causes intermolecular distances to become shorter. However, it is possible that for several distances this will not be the case (for instance when molecules will change their mutual orientation). Such a situation takes place for the BBCP crystals at 0.5 and $0.7 \mathrm{GPa}$, for which the distance between reactive carbon atoms in adjacent monomer molecule, $D$, is almost constant: 3.962(13) and 3.954(13) $\AA$ for the crystal containing 8.8(9)\% of the product at $0.5 \mathrm{GPa}$ and the crystal containing $12.1(7) \%$ of the product at $0.7 \mathrm{GPa}$, respectively, and also 3.80(3) and 3.82(3) ̊ for the crystal containing $54.4(11) \%$ of the product at $0.5 \mathrm{GPa}$ and the crystal containing $49.3(13) \%$ of the product at $0.7 \mathrm{GPa}$, respectively. This clearly indicates that the distance between reactive carbon atoms is not the reason for the higher reactivity of BBCP at $0.7 \mathrm{GPa}$. It should be emphasized that the constancy of $D$ at 0.5 and $0.7 \mathrm{GPa}$ exists despite the decrease in the cell volume and all cell parameters at $0.7 \mathrm{GPa}$.

The next factor which should be taken into account is connected with the cell volume. In the case of BBCP studied
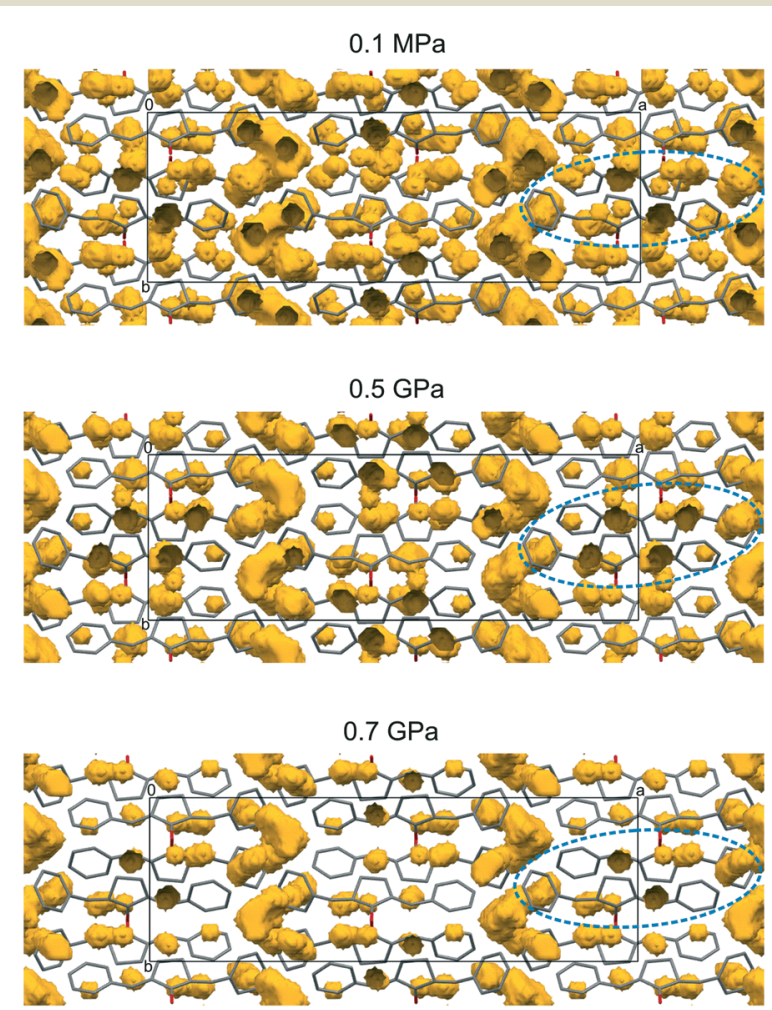

Fig. 3 The crystal lattice for the following reaction progress: $55.6(4) \%$, $54.4(11) \%$ and $49.3(13) \%$ at $0.1 \mathrm{MPa}, 0.5 \mathrm{GPa}$ and $0.7 \mathrm{GPa}$, respectively. The free space is shown in yellow. The dashed line indicates one pair of the monomer molecules which will create the dimer. The product molecules were omitted. The figure was prepared with the Mercury CSD 3.8 program. ${ }^{37}$ The radius of the rolling ball was $0.6 \AA$ and the grid was $0.2 \AA$. The part of the figure concerning $0.1 \mathrm{MPa}$ was prepared on the grounds of data taken from ref. 3 (CCDC 154258; REFCODE: BZDCPB01). 
at ambient pressure, it was observed that the cell volume decreased along with the reaction progress; however, that decrease was not very high. ${ }^{3}$ In general, consistency between the direction of structural changes brought about by a reaction and by high pressure should make the reaction easier. $^{7,8,12}$ This means that due to the decrease in the cell volume with the reaction progress, the photochemical reaction of BBCP should be faster at higher pressure.

Nevertheless, other factors exist which could counteract the influence of the aforementioned factor. One of them is the volume of free space, which should be taken into account not only before but also during the whole phototransformation. Such a volume for the crystals with a $50 \%$ reaction progress is presented in Fig. 3. As can be seen, the free space in the crystal and also in the region of two reacting monomer molecules (marked by the dashed line) decreases en route from $0.1 \mathrm{MPa}$ to $0.7 \mathrm{GPa}$. A decrease of free space usually makes a reaction more difficult. However, in the case of BBCP, the dimer molecules fit very well to the lattice of the monomer molecules and do not demand additional space (see Fig. 1). This suggests that the observed decrease in free space is not crucial for the BBCP reactivity.

The strong intermolecular interactions are the next factor which could influence the rate of the $[2+2]$ photodimerization of BBCP at high pressure. The intermolecular interactions of the compound were visualized by the Hirshfeld surfaces. Fig. 4. presents such surfaces for the crystal with about a $50 \%$ reaction progress at $0.1 \mathrm{MPa}, 0.5 \mathrm{GPa}$
Table 3 The geometry of the intermolecular contacts (the contacts are shown in Fig. 4)

\begin{tabular}{|c|c|c|c|c|}
\hline & $\mathrm{D}-\mathrm{H}[\AA]$ & $\mathbf{H} \cdots \mathbf{A}[\AA]$ & $\mathrm{D} \cdots \mathrm{A}[\AA]$ & $\mathrm{D}-\mathrm{H} \cdots \mathrm{A}\left[{ }^{\circ}\right]$ \\
\hline \multicolumn{5}{|l|}{$0.1 \mathrm{MPa}$} \\
\hline $\begin{array}{l}\mathrm{C} 2 \mathrm{M}-\mathrm{H} 2 \mathrm{M} \cdots \mathrm{O} 1 \mathrm{M}^{\mathrm{i}} \\
0.5 \mathrm{GPa}\end{array}$ & 0.98 & 2.45 & $3.286(4)$ & 143.3 \\
\hline $\mathrm{C} 2 \mathrm{M}-\mathrm{H} 2 \mathrm{M} \cdots \mathrm{O} 1 \mathbf{M}^{\mathrm{i}}$ & 0.98 & 2.38 & $3.215(17)$ & 142.6 \\
\hline C3M-H3M1 $\cdots$ C19M $^{\mathrm{ii}}$ & 0.97 & 2.70 & $3.65(7)$ & 167.2 \\
\hline C8M-H8M $\cdots$ C18M $^{\mathrm{ii}}$ & 0.95 & 2.68 & $3.57(11)$ & 154.6 \\
\hline C10M-H10M $\cdots$ C8M $^{\mathrm{iii}}$ & 0.95 & 2.84 & $3.74(4)$ & 159.4 \\
\hline C17M-H17M $\cdots$ C10M $^{\text {iv }}$ & 0.95 & 2.75 & $3.47(6)$ & 132.8 \\
\hline C18M-H18M $\cdots$ C9M $^{v}$ & 0.95 & 2.75 & $3.41(9)$ & 128.1 \\
\hline \multicolumn{5}{|l|}{$0.7 \mathrm{GPa}$} \\
\hline $\mathrm{C} 2 \mathrm{M}-\mathrm{H} 2 \mathrm{M} \cdots \mathrm{O} 1 \mathrm{M}^{\mathrm{i}}$ & 0.98 & 2.35 & $3.185(14)$ & 142.6 \\
\hline C10M-H10M $\cdots \mathrm{C}^{2} \mathrm{M}^{\mathrm{iii}}$ & 0.95 & 2.71 & $3.62(2)$ & 162.8 \\
\hline C18M-H18M $\cdots$ C9M $^{v}$ & 0.94 & 2.79 & $3.49(8)$ & 133.0 \\
\hline C17M-H17M $\cdots C^{2} 10 M^{\text {vi }}$ & 0.95 & 2.84 & $3.59(4)$ & 137.6 \\
\hline C9M-H9M $\cdots \mathrm{C} 11 \mathrm{M}^{\mathrm{vii}}$ & 0.94 & 2.78 & $3.66(3)$ & 155.3 \\
\hline 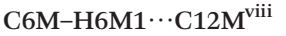 & 0.97 & 2.80 & $3.55(3)$ & 134.0 \\
\hline
\end{tabular}

Symmetry codes: $\mathrm{i}=x, 1.5-y, 0.5+z ; \mathrm{ii}=1-x, 1-y,-z ;$ iii $=0.5-$ $x, 1-y, 0.5+z ; \mathrm{iv}=0.5+x, y, 0.5-z ; \mathrm{v}=1-x, 0.5+y, 0.5-z ; \mathrm{vi}=1$ $-x, 1-y, 1-z$, vii $=0.5-x,-0.5+y, z$, viii $=x, 1.5-y,-0.5+z$.

and 0.7 GPa and the geometry of close intermolecular interactions is given in Table 3. Interestingly, four red spots seen at $0.5 \mathrm{GPa}$ on the Hirshfeld surface and connected with the $\mathrm{C}-\mathrm{H} \cdots \mathrm{C}$ interactions with the partnering monomer molecule disappeared at $0.7 \mathrm{GPa}$ (despite the smaller cell parameters and the cell volume at $0.7 \mathrm{GPa}$ ). This signifies that the

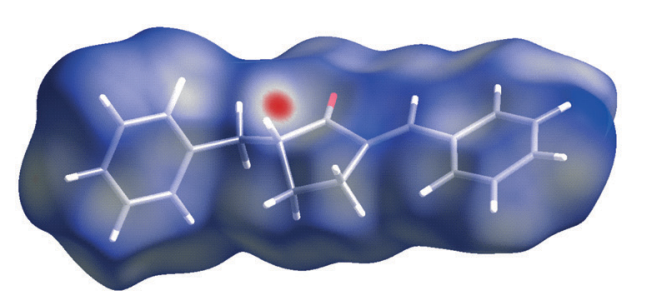

$0.1 \mathrm{MPa}$
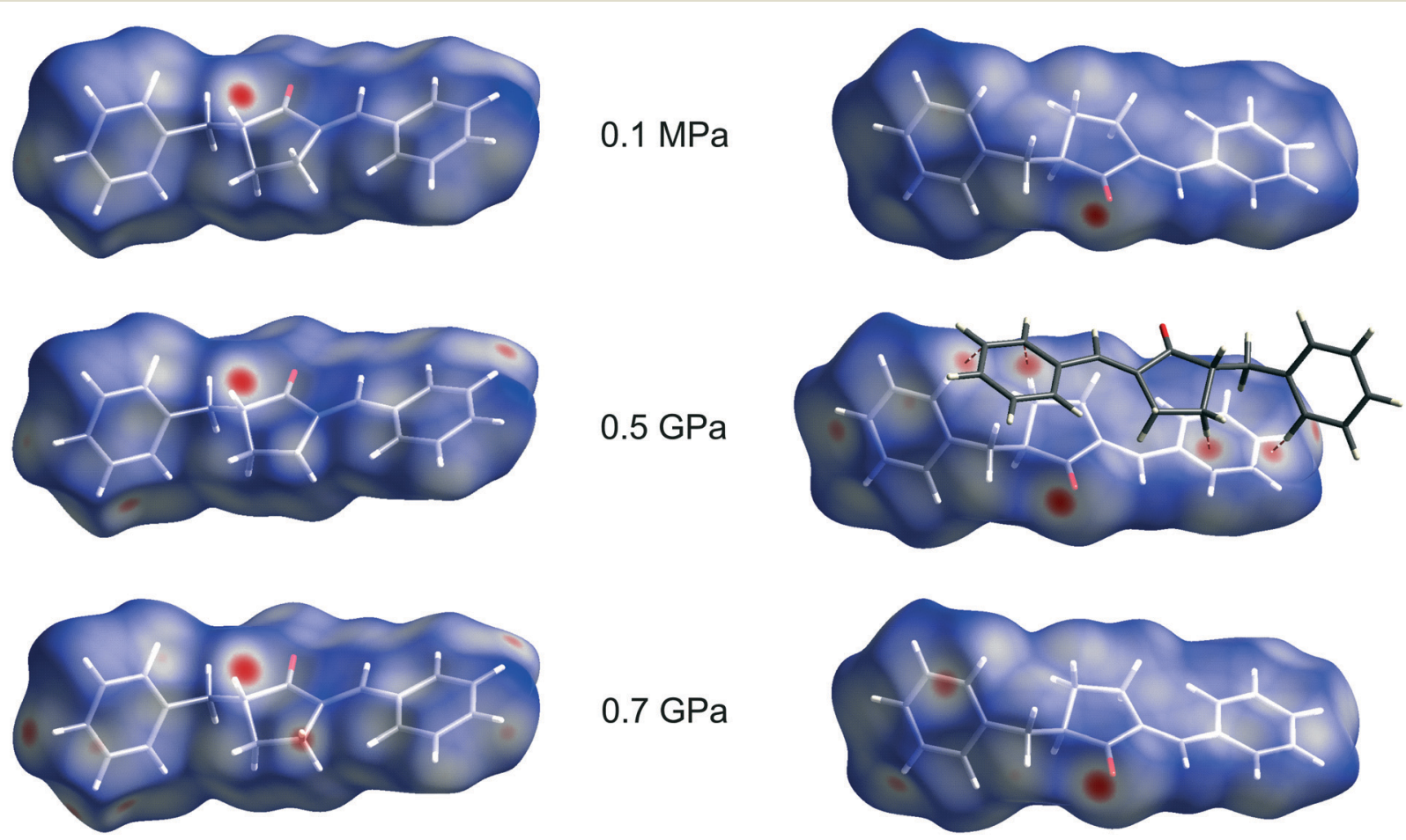

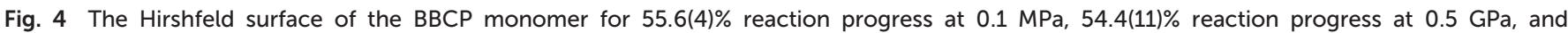

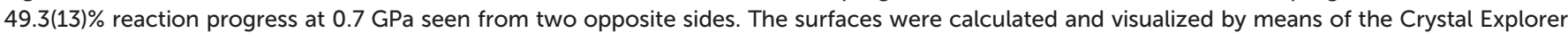

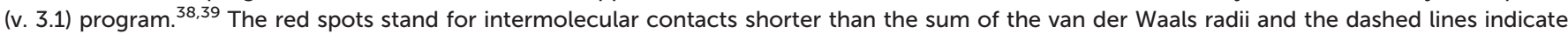
contacts between the molecule inside the Hirshfeld surface (white) and the monomer molecule which will react with it (dark grey). 
mutual arrangement of the monomer molecules is slightly different at both pressures. It can also be seen in Fig. 4 that at $0.7 \mathrm{GPa}$ there are shorter $\mathrm{C}-\mathrm{H} \cdots \mathrm{C}$ interactions with other surrounding molecules. Since all the above-mentioned contacts are rather far from the reaction centre, they should not have a significant influence on atomic shifts in the reaction centre and on the BBCP reactivity. (The red spot which appeared at atom $\mathrm{C} 4 \mathrm{M}$ at $0.7 \mathrm{GPa}$ stands for a weak $\mathrm{H} \cdots \mathrm{H}$ interaction.)

Taking into account the above considerations, it can be said that the decrease in the cell volume with the reaction progress is the reason for the increase in the reaction rate at $0.7 \mathrm{GPa}$ and that the $D$ distance between reactive atoms, the volume of free space and the intermolecular interactions are not the factors which bring about this increase.

From the above-given values of the $D$ distance at 0.5 and $0.7 \mathrm{GPa}$, it is seen that $D$ decreases during the photochemical transformation of BBCP crystals. We might ponder the question: is this trend valid for the whole process? In the case of the $[2+2]$ photodimerization of BBCP and the derivative of BBCP (2-benzylidene-5-(4-chlorobenzyl)cyclopentanone, $\mathrm{BBCPCl}$ ) under ambient conditions, the distance between reactive carbon atoms in adjacent monomer molecules decreased during the whole crystal phototransformation. ${ }^{3,40,41}$ That relationship was explained by the increase of stress of product molecules imposed on reactant molecules: the more the product, the stronger the effect. Fig. 5 presents the relationship between the $D$ distance and the content of the product for BBCP at $0.5 \mathrm{GPa}$ in comparison to the relevant data for $0.1 \mathrm{MPa}$. In the case of high pressure, the decrease is observed only during the first part of the phototransformation and it is statistically significant at the $3 \sigma$ level. In comparison to ambient conditions, the slope of the line fitted to the high-pressure data is bigger, which indicates that the stress induced by product molecules on monomer pairs is more effective at high pressure. After the observed decrease, the $D$ distance becomes statistically constant at the $3 \sigma$ level, which

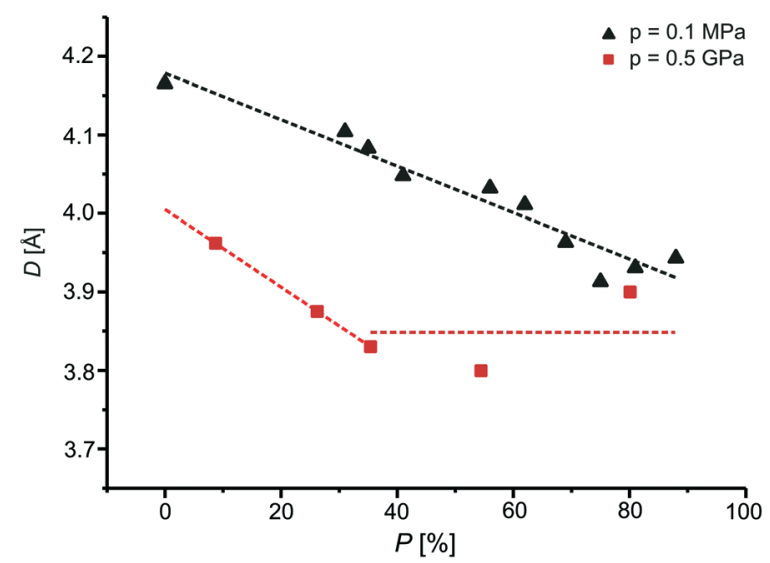

Fig. 5 The relationship between the distance between reactive carbon atoms and the content of the product in the crystal of BBCP at 0.1 $\mathrm{MPa}$ and $0.5 \mathrm{GPa}$. The part of the figure concerning 0.1 $\mathrm{MPa}$ was prepared on the grounds of data taken from ref. 3 . shows a certain limit of effectiveness of stress imposed by product molecules on monomer pairs resulting from closer intermolecular distances between monomer molecules at 0.5 GPa. The decrease of the $D$ distance was also noticed for the first part of the photochemical transformation in the crystals of 2,6-difluorocinnamic acid at high pressure. ${ }^{14}$
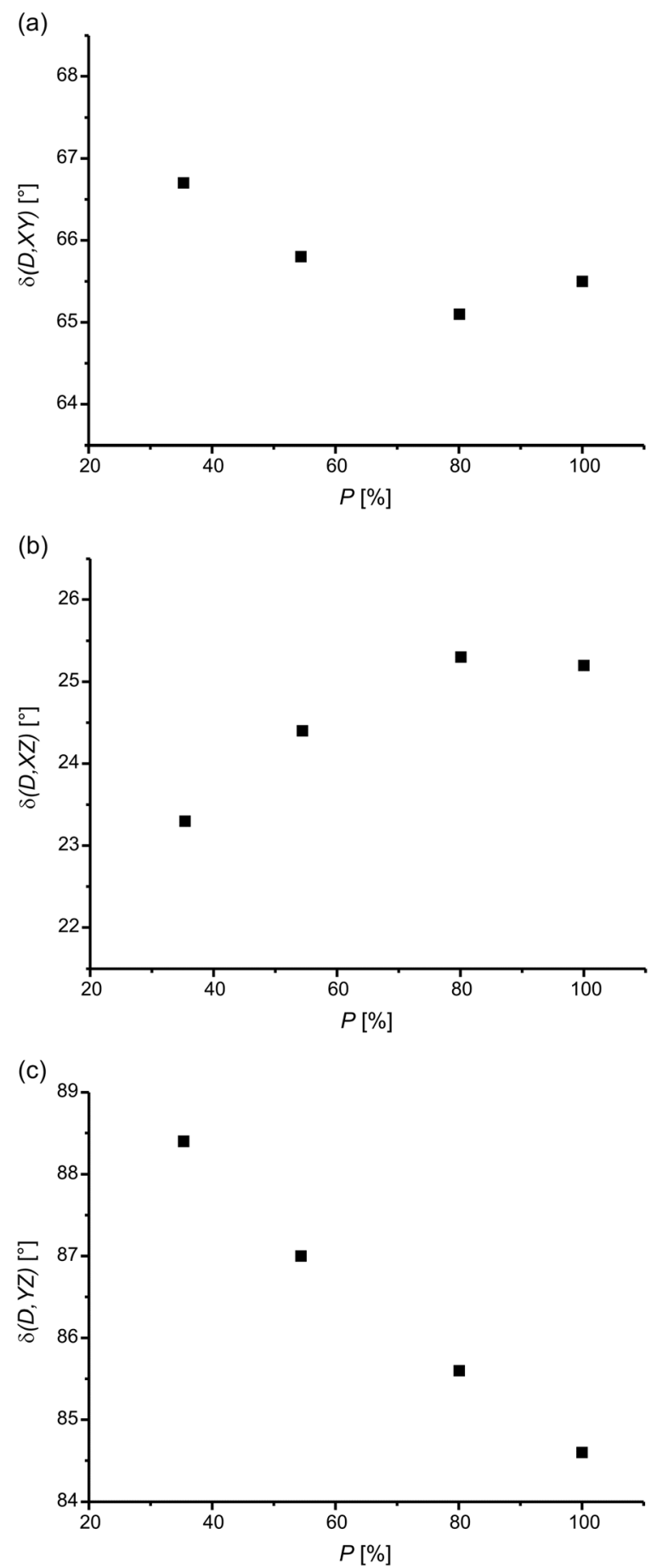

Fig. 6 The variations in the angle between the best dimer molecule plane and a) $X Y$, b) $X Z$ and c) $Y Z$ along with the reaction progress at 0.5 $\mathrm{GPa}$. For better comparison with the relevant data for ambient pressure, the points for the reaction progress larger than $30 \%$ were shown. 
The $[2+2]$ photodimerization of $\mathrm{BBCP}$ at high pressure causes changes in the orientation of molecules and molecular fragments in the unit cell. Fig. 6 shows the changes in the orientation of the dimer molecule along with the reaction progress at $0.5 \mathrm{GPa}$. The comparison of these relationships with the relevant data for ambient pressure reveals that the direction and extent of the changes are very similar at both pressures. As can also be seen, the structural changes are smooth at high pressure. This was the same for ambient conditions. ${ }^{3}$

The positions of atoms change along with the progress of the photochemical reaction, the consequence of which is the changes in the cell parameters. The variations in the cell volume of BBCP for different values of pressure are shown in Fig. 7. The cell volume does not change in the first part of the crystal phototransformation, but alters slightly in the remaining part, which is connected with the similar shape of the dimer and one pair of the monomers. The range of the changes in the cell volume caused by the $[2+2]$ photodimerization is quite similar for ambient and high pressures.

High pressure itself (without the photochemical reaction) influences the weak geometrical parameters such as intermolecular contacts and intramolecular torsion angles, but it does not influence the hard geometrical parameters such as

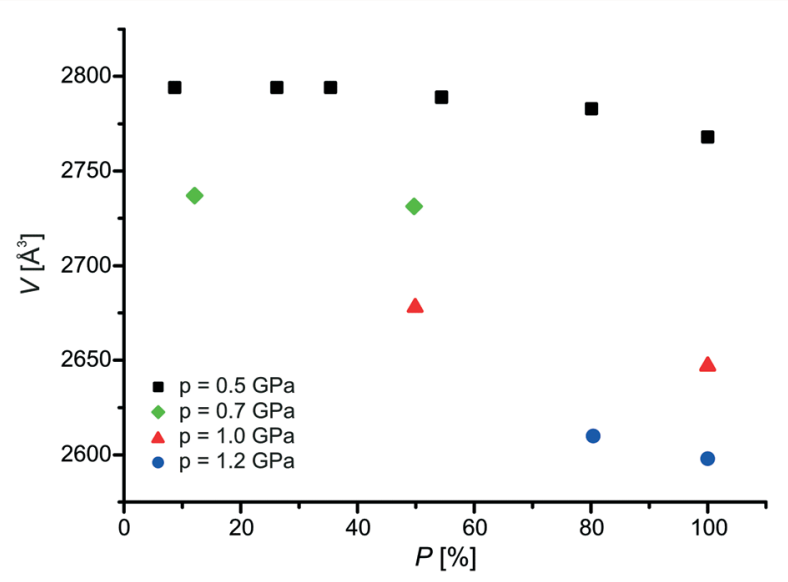

Fig. 7 The variations in the cell volume along with the percentage content of the product for $0.5 \mathrm{GPa}, 0.7 \mathrm{GPa}, 1.0 \mathrm{GPa}$ and $1.2 \mathrm{GPa}$.

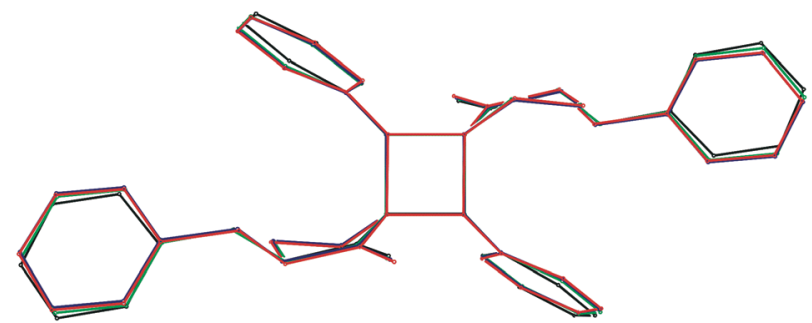

Fig. 8 The superposition of the dimer molecules for $0.1 \mathrm{MPa}$ (black), $0.5 \mathrm{GPa}$ (green), 1.0 GPa (blue) and 1.2 $\mathrm{GPa}$ (red). Hydrogen atoms are omitted for clarity. The part of the figure concerning $0.1 \mathrm{MPa}$ was prepared on the grounds of the data taken from ref. 3 . bond lengths and valence angles of BBCP. From Fig. 8 it is seen that the shape of BBCP molecules only depends slightly on the pressure applied. The same was observed for other compounds studied at high pressure. ${ }^{11,12,14}$

\section{Conclusions}

We presented the results on monitoring the structural changes that came about by the $[2+2]$ photodimerization in crystals of BBCP at high pressure. This is one of the two first examples of such studies for an intermolecular reaction. On the grounds of the comparison of the high pressure structural data with the relevant data under ambient conditions, we can say that the influence of pressure of $0.5 \mathrm{GPa}$ on (a) the extent of the changes in the cell volume caused by the photochemical reaction, (b) the extent of variations in molecular orientation during the crystal phototransformation and (c) the decrease of the $D$ distance between the reactive atoms brought about by the stress of product molecules are the same or very similar. However, the character of the changes in the $D$ distance is different for $0.1 \mathrm{MPa}$ and $0.5 \mathrm{GPa}$. The reason for the observed close similarity between the reaction path at both pressures is a very good fit for dimer molecules to the crystal lattice of the monomer. We also discovered that the photochemical reactivity of $\mathrm{BBCP}$ is greater at $0.7 \mathrm{GPa}$ than $0.5 \mathrm{GPa}$ (however, the difference is not very significant) and explained this fact by the consistency between structural changes caused by the photochemical reaction and by high pressure.

\section{Acknowledgements}

This work was financed by the statutory activity subsidy of the Polish Ministry of Science and Higher Education.

\section{References}

1 H. Nakanishi, W. Jones, J. M. Thomas, M. B. Hursthouse and J. M. Motevalli, J. Phys. Chem., 1981, 85, 3636-3642.

2 K. Honda, F. Nakanishi and N. Feeder, J. Am. Chem. Soc., 1999, 121, 8246-8250.

3 I. Turowska-Tyrk, Chem. - Eur. J., 2001, 7, 3401-3405.

4 I. Turowska-Tyrk, Chem. Phys. Lett., 2002, 361, 115-120.

5 G. Kaupp, Curr. Opin. Solid State Mater. Sci., 2002, 6, 131-138.

6 E. V. Boldyreva, Solid State Ionics, 1997, 101-103, 843-849.

7 E. V. Boldyreva, S. L. Kuzmina and H. Ahsbahs, J. Struct. Chem., 1998, 39, 762-773.

8 E. V. Boldyreva, Russ. J. Coord. Chem., 2001, 27, 297-323.

9 M. Tapilin, N. N. Bulgakov, A. P. Chupakhin, A. A. Politov and A. G. Druganov, J. Struct. Chem., 2010, 51, 635-641.

10 B. A. Zakharov, A. S. Marchuk and E. V. Boldyreva, CrystEngComm, 2015, 17, 8812-8816.

11 J. Bąkowicz and I. Turowska-Tyrk, CrystEngComm, 2014, 16, 6039-6048. 
12 K. Konieczny, J. Backowicz and I. Turowska-Tyrk, CrystEngComm, 2015, 17, 7693-7701.

13 K. Konieczny, J. Backowicz and I. Turowska-Tyrk, J. Photochem. Photobiol., A, 2016, 325, 111-115.

14 T. Galica, J. Bąkowicz, K. Konieczny and I. Turowska-Tyrk, CrystEngComm, 2016, DOI: 10.1039/c6ce01652a.

15 E. V. Boldyreva, S. L. Kuzmina and H. Ahsbahs, J. Struct. Chem., 1998, 39, 343-349.

16 E. V. Boldyreva, D. Yu. Naumov and H. Ahsbahs, J. Struct. Chem., 1998, 39, 350-361.

17 R. Boehler, Rev. Sci. Instrum., 2006, 77, 115103.

18 L. Merrill and W. A. Bassett, Rev. Sci. Instrum., 1974, 45, 290-294.

19 R. J. Angel, D. R. Allan, R. Miletich and W. Finger, J. Appl. Crystallogr., 1997, 30, 461-466.

20 A. Budzianowski and A. Katrusiak in High-Pressure Crystallography, ed. A. Katrusiak and P. F. McMillan, Kluwer Academic Publishers, Dordrecht Boston London, 2004, pp. 101-112.

21 Rigaku Oxford Diffraction, CrysAlis PRO., Rigaku Oxford Diffraction, Wrocław, Poland, 2015.

22 V. Enkelmann, G. Wegner, K. Novak and K. B. Wagener, J. Am. Chem. Soc., 1993, 115, 10390-10391.

23 K. Novak, V. Enkelmann, G. Wegner and K. B. Wagener, Angew. Chem., Int. Ed. Engl., 1993, 32, 1614-1616.

24 G. M. Sheldrick, Acta Crystallogr., Sect. A: Found. Crystallogr., 2008, 64, 112-122.

25 G. M. Sheldrick, Acta Crystallogr., Sect. C: Struct. Chem., 2015, 71, 3-8.

26 L. J. Farrugia, J. Appl. Crystallogr., 2012, 45, 849-854.

27 M. Avrami, J. Chem. Phys., 1939, 7, 1103-1112.

28 W. A. Johnson and R. F. Mehl, Trans. Am. Inst. Min. Metall. Eng., 1939, 135, 416-458.
29 A. N. Kolmogorov, Bull. Acad. Sci. USSR, Math. Ser., 1937, 1, 355-359.

30 J. Bąkowicz, J. Olejarz and I. Turowska-Tyrk, J. Photochem. Photobiol., A, 2014, 273, 34-42.

31 N. K. Nath, T. Runčevski, C.-Y. Lai, M. Chiesa, R. E. Dinnebier and P. Naumov, J. Am. Chem. Soc., 2015, 137, 13866-13875.

32 T. V. Sreevidya, D.-K. Cao, T. Lavy, M. Botoshansky and M. Kaftory, Cryst. Growth Des., 2013, 13, 936-941.

33 A. G. Jarvis, H. A. Sparkes, S. E. Tallentire, L. E. Hatcher, M. R. Warren, P. R. Raithby, D. R. Allan, A. C. Whitwood, M. C. R. Cockett, S. B. Duckett, J. L. Clark and I. J. S. Fairlamb, CrystEngComm, 2012, 14, 5564-5571.

34 M. Bertmer, R. C. Nieuwendaal, A. B. Barnes and S. E. Hayes, J. Phys. Chem. B, 2006, 110, 6270-6273.

35 R. Moré, G. Busse, J. Hallmann, C. Paulmann, M. Scholz and S. Techert, J. Phys. Chem. C, 2010, 114, 4142-4148.

36 J. B. Benedict and P. Coppens, J. Phys. Chem. A, 2009, 113, 3116-3120.

37 C. F. Macrae, P. R. Edgington, P. McCabe, E. Pidcock, G. P. Shields, R. Taylor, M. Towler and J. van de Streek, J. Appl. Crystallogr., 2006, 39, 453-457.

38 M. A. Spackman and D. Jayatilaka, CrystEngComm, 2009, 11, 19-32.

39 S. K. Wolff, D. J. Grimwood, J. J. McKinnon, M. J. Turner, D. Jayatilaka and M. A. Spackman, CrystalExplorer (Version 3.0), University of Western Australia, 2012.

40 I. Turowska-Tyrk, Acta Crystallogr., Sect. B: Struct. Sci., 2003, 59, 670-675.

41 I. Turowska-Tyrk, J. Phys. Org. Chem., 2004, 17, 837-847. 